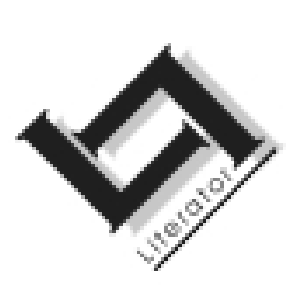

\title{
Die insluiting van 'n (multi-)kulturele komponent in die kurrikulum vir Afrikaans as addisionele taal
}

\author{
Estelle Kruger \\ Departement Didaktiek van Afrikaans \\ Universiteit van Stellenbosch \\ STELLENBOSCH \\ E-pos: ekruger@maties.sun.ac.za
}

\begin{abstract}
The inclusion of a (multi-)cultural component in the curriculum for Afrikaans as additional language
\end{abstract}

In this article the author pleads for a democratisation of Afrikaans as an additional language curriculum so that the teaching and learning of Afrikaans could contribute towards cross-cultural consciousness. Relevant definitions of the concept culture are discussed, as well as intercultural understanding, stereotyping and communication. The relationship between literature, culture and cognitive development as well as culture and nonverbal communication is perused. Several ways are indicated by which culture could be integrated into a communicative Afrikaans language programme, such as giving attention to different sociolinguistic speech routines, including authentic media texts, as well as the study of folklore and stereotypes in literary texts (with examples of each of these cultural components). Broadening the learning content in this way could assist in neutralising the negative effects of the political-historical past of the Afrikaans language. This aim can be reached if the non-mother tongue learner's interests are stimulated and his/her needs are addressed. Being involved in and exposed to these kinds of cultural components in Afrikaans, the learners would feel at home in the additional language classroom. Consequently they would feel free to participate actively - both emotionally and cognitively - and would ultimately accept responsibility for their own learning. 


\section{Inleiding}

Die onderwyssituasie in Suid-Afrika het met die eeuwending unieke kenmerke verkry, onder andere dat die makrokosmos van 'n nuwe organisasie van die samelewing in die mikrokosmos van die klaskamer weerspieël word. Min klassituasies bied soveel potensiaal wat ontgin kan word as die taalklaskamer. Hieronder val Afrikaans as addisionele taal1, wat ongelukkig nie deur alle opvoeders as 'n taal met hoë prioriteit beskou word nie - enersyds vanweë die negatiewe politieke stigma wat aan Afrikaans kleef, en andersyds omrede die onsekerheid wat met verandering gepaard gaan. Tog skep verandering juis 'n opwindende geleentheid vir vernuwing en oorspronklikheid.

In die kurrikulum van Afrikaans as addisionele taal is die tyd ryp dat 'n verruiming van leerinhoud moet plaasvind. Die insluiting van 'n kulturele komponent kan sodanige vernuwing teweegbring. In die uitkomsgebaseerde onderwysbenadering word nie net gespesifiseer dat leerders moet kan reageer op estetiese, emosionele, kulturele en sosiale waardes van tekste nie; daar word ook van opvoeders verwag om gedurig te konsentreer op die ontwikkeling van leerders se vermoë om kulturele en estetiese sensitiwiteit te openbaar in verskillende sosiale tekste.

Omdat daar nog relatief min empiriese navorsing bestaan oor Afrikaans waarop die argument aangaande die insluiting van 'n kulturele komponent gebaseer kan word, sal in hierdie artikel meestal gesteun word op bevindings van navorsing wat gedoen is oor die onderrig van Engels as vreemde of tweede taal, sowel as ander studies met studente in Afrikaans-tweedetaalkontekste. Die uiteindelik visie wat hier aangebied word, is gebaseer op eie ervaring met Zoeloesprekende onderwysstudente (in Pietermaritzburg). Verder het die aanleer van Nederlands tydens 'n kulturele toer deur Nederland en België by my ' $n$ bewustheid aangewakker vir die gevoelens en ervarings wat gepaard gaan met die aanleer van 'n addisionele taal en die belangrike rol wat kultuur daarin kan speel.

In ooreenstemming met Kamwangamalu (1997:244) se argument vir die onderrig van Engels aan nie-moedertaalleerders, word gepleit vir 'n demokratisering van 'n kurrikulum vir Afrikaans as addisionele taal, wat sal poog om allerlei komponente van verskillende kulture (bv. waardes,

1 Daar kan tereg geargumenteer word dat Afrikaans vir die meeste Afrikataalsprekers 'n vreemde taal is (Hamersma, 1997:290), veral omdat hulle blootstelling aan die taal veral deesdae baie beperk is. In hierdie artikel sal voortaan egter verwys word na Afrikaans as addisionele taal om te pas by die nuutste beleidsdokument (Department of Education, 1997), waar alleenlik onderskei word tussen primêre en addisionele tale. 
gelowe, tradisies, ens.) in te sluit. So 'n kurrikulum kan lei tot die skep van 'n holistiese multikulturalisme - wat Lewins (aangehaal deur Kamwangamalu, 1997:244) sien as onderlinge begrip en verdraagsaamheid binne die konteks van eenheid en verskeidenheid. Moyo (1997:44) meen dat die inherente leerprobleme wat voorkom wanneer studente ' $n$ addisionele taal moet bemeester, verminder kan word as 'n kulturele en kruiskulturele bewussyn in skole 'n prioriteit is. Met laasgenoemde in ag genome, sal aangetoon word hoe taal gesitueer kan word binne 'n bekende konteks vir leerders.

Verskillende definisies van kultuur kan lig werp op die verband tussen taal as sosio-kulturele verskynsel, letterkunde en die kognitiewe ontwikkeling van leerders. Dit kan die opvoeder uiteindelik help om interkulturele begrip en kommunikasie in 'n taalonderrigprogram te integreer. Verskeie voorbeelde van sosiolinguistiese spraakpatrone, letterkundige en alledaagse outentieke tekste sal genoem word wat as voorbeelde vir die integrasie van kultuur in 'n kommunikatiewe taalprogram kan dien.

\section{Kultuur en die aanleer van taal}

Die rede waarom leesmateriaal gebaseer moet wees op kulturele aspekte, is omdat die materiaal iets behoort te bied waarmee die leerders kan identifiseer. Zulu (1996:53) verwys na Evans se navorsingsbevindings wat aantoon dat (Engels-) tweedetaalleerders ' $n$ beter begrip toon vir tekste wat gebaseer is op hulle eie kultuur as vir tekste wat gebaseer is op ander kulture - selfs al is die inhoude daarvan linguisties en retories eenders.

Lessing en De Witt (1999:49) glo dat dit noodsaaklik is dat taalopvoeders begrip moet hê vir die wyse waarop kulturele elemente onderrig en leer beïnvloed, omdat alle mense deel van 'n dinamiese kulturele proses is. Om hierdie rede sal enkele definisies van "kultuur" en die relevansie daarvan vir die leerinhoud eers bespreek word. Daarna sal die toepassing van hierdie kennis in die taalaanleerkonteks bespreek word.

\subsection{Relevante definisies van kultuur}

Scovel (Moyo, 1997:44) omskryf kultuur as "the tangible symbols, interest values that people use to define themselves and the social element of all human relationship ... and the medium in which we move and breathe and have our being".

Met die bespreking van hierdie definisie beklemtoon Moyo dat kultuur die fundamentele bewussyn van menswees omsluit. Hy gebruik die metafoor 
"kulturele ysberg" vir minder duidelike aspekte van kultuur wat juis kan veroorsaak dat taalleerders 'n teks met 'n agtergrond vreemd aan hul kultuur glad nie verstaan nie. Moyo voer aan dat leerders deur middel van tekste wat gesitueer is in 'n (vir hulle) bekende agtergrond, leer om aan te pas in die kultuur van die teikentaalgroep. Dit is betekenisvol vir hierdie argument dat iemand soos Moyo (waarskynlik afkomstig uit 'n nie-Europese kultuur), op hierdie manier Afrika-taalleerders se belangstelling (of gebrek aan belangstelling) in tekste analiseer en verklaar.

Voorbeelde van hierdie tasbare, sigbare simbole wat deel uitmaak van die kultuur, wat mense met mekaar deel en waardeur hulle met mekaar kommunikeer, kan die volgende insluit: kunsuitinge (verbaal, musikaal, dans, beeldende kuns), godsdienstige en alledaagse gebruike en gewoontes, vermaaklikheid en vorme van vryetydsbenutting. In 'n multikulturele klas kan hierdie kultuurkomponente geïntegreer word in onderrigprogramme en leerders kan van mekaar kennis neem en mekaar leer respekteer. Combrink (1996:7) sluit hierby aan en bespreek die noodsaak daarvan dat kulturele geletterdheid onderrig moet word om leerders voor te berei om self kultuurskeppers te wees. Sy bespreek die ideologiese en implisiete (materiële) aspekte van kultuur en meen dat kultuur in die wydste sin beskryf kan word as "alles wat deur mense geskep word in sosiale interaksie, alles wat die mens gedoen het en tans doen. Mens erf én skep kultuur; kultuur is sowel die individu as die groep se volledige lewenswyse" (Combrink, 1996:2).

In 'n soortgelyke bespreking van 'n kulturele komponent in taalkurrikula gebruik Kamwangamalu (1997:245) verskeie definisies om te beklemtoon dat amper alles in 'n taalkursus daartoe in staat is om 'n kulturele lading te dra, want "culture is the socially learned, shared assemblage of practices, perceptions, attitudes, world views, value systems and beliefs that determine the texture of our lives as members of a given community".

Taal speel 'n belangrike rol in enige kultuur. Kamwangamalu (1997:246) kom self uit 'n Afrika-kultuur en betoog dat die kulturele aspekte van voorheen gemarginaliseerde groepe geïntegreer behoort te word in die temas, leermateriaal en aktiwiteite in 'n taalklaskamer, sodat leerprogramme kultuursensitief kan wees. Trivedi (1978:92) meen dat vreemde- of tweedetaalonderrig onder andere behels dat die leerder se (aangeleerde) gedrag verander sal word in dié sin dat 'n nuwe lewenswyse en nuwe lewenswaardes toegevoeg sal word tot die reeds bestaande kultuur van die leerder.

Trivedi (1978:93) lê veral klem op die hele kwessie van waarde-oordrag in die vreemde- of tweedetaalklaskamer. Melding word gemaak van 
emosionele probleme wat vreemdetaalleerders ervaar en wat hindernisse kan wees in die leerproses. Hierdie emosionele probleme kan die volgende insluit: gevoelens van skok of hulpeloosheid, taalangs of vrees vir mislukking om kultuuroordrag te interpreteer of te verstaan. Op grond van eie ervaring met Zoeloesprekende onderwysstudente is gevind dat die insluiting van (vir hulle bekende) kulturele inhoude daartoe bygedra het dat hulle in die addisionele klaskamer vry voel om hulself uit te druk en spontaan deel te neem aan aktiwiteite. Hulle taalangs is dus hierdeur verminder en hul motivering verhoog.

Robinson (1995:7-11) onderskei en analiseer verskeie beskouings van "kultuur" (dié van onderwysers, behaviouriste, funksionaliste, sowel as kognitiewe en simboliese definisies). Wat belangrik is, is Robinson se bevindings op grond van eie ervaring met ander kulture sowel as navorsing, wat gelei het tot die aanbeveling dat die integrasie van kultuur in 'n taalprogram 'n sintese behoort te wees tussen die leerder se tuiskultuur (home culture), die teikenkulturele toevoer en die leerder as individu. Dit gebeur dikwels dat nie-moedertaalsprekers se Afrikaans "stokkerig" en onnatuurlik klink in die oor van die moedertaalspreker. Hierdie verskynsels kom waarskynlik voor omdat hulle die taal akademies aangeleer het, sonder om die idiomatiese ondertone ("tussen die lyne") te onderskei. Hulle ken die taal dus sonder die kulturele, implisiete betekenisregisters waaroor moedertaalsprekers intuïtief beskik en instinkmatig gebruik. En almal weet hoe oorspronklik dit klink as 'n anderstalige spreker self een van hul eie moedertaal-idiome in Afrikaans "vertaal".

Adaskou et al. (1990:3, 4) onderskei estetiese, sosiologiese, semantiese en pragmatiese (sosiolinguistiese) betekenisse van die term "kultuur". In die verlede is reeds baie klem gelê op die estetiese betekenis van kultuur (musiek, poësie, prosa, beeldende kunste en drama), en die gewone verbale vorme word reeds geredelik ingesluit in die kurrikula vir die aanleer van addisionele tale in Suid-Afrika (bv. kortverhale, liedjies en gedigte). Dit is egter veral die insluiting van die pragmatiese en sosiologiese betekenisse van kultuur wat in hierdie artikel uitgelig en beklemtoon word.

Behalwe 'n begrip van die konsep "kultuur" se onderskeie betekenisse, moet die taalopvoeder bewus wees van moontlike stereotipering en die invloed daarvan op interpersoonlike kommunikasie om toegerus te kan wees vir die onderrig van interkulturele begrip. 


\subsection{Interkulturele begrip, stereotipes en kommunikasie}

Robinson $(1995: 4,5)$ meen dat interkulturele begrip gebaseer is op perseptuele kongruensie (fisiologies, emosioneel, kinesteties en sensories). Wedersydse kulturele begrip beteken dat elke persoon wat betrokke is, kulturele aanpasbaarheid sal moet ontwikkel en dit behels "modifying one's own cultural repertoire". Die implikasie hiervan vir die onderrigprogram van Afrikaans as 'n addisionele taal is dat die kulturele ervaring van die leerder ingesluit en toegepas moet word in die hele leeromgewing. Robinson waarsku egter dat die kennis van verskille tussen kulture leerders onderling kan verdeel, omdat dit mag lei tot stereotipering, terwyl dit die bestudering van ooreenkomste is wat eerder sal kan lei tot interkulturele begrip. Bredella en Haack (1988:12) bespreek ook die hele kwessie van interkulturele begrip en kom tot die gevolgtrekking dat "a foreign culture challenges our basic assumptions and demands that we reconstruct the original context of a culture in order to understand its symbols in terms of the people who have created them".

Vir die taalopvoeder is dit belangrik om kennis te neem van die moontlikheid van stereotipering by die insluiting van 'n kulturele komponent in die kurrikulum en om te waak teen die negatiewe implikasies daarvan. Stereotipering is egter nie vir Bredella en Haack (1988:8) op sigself 'n probleem nie. Hulle gebruik Lippmann (1922) se argument om die positiewe potensiaal van stereotipes raak te sien, naamlik dat dit die waarnemer help om 'n ingewikkelde werklikheid te vereenvoudig, te kategoriseer en daardeur dinge en gebeure met mekaar te verbind. Uiteindelik is Lippman (aangehaal deur Bredella \& Haack, 1988:9) se advies:

... not to try and give up stereotypes but to learn to use them in a reflective and self-critical way ... the insight into the selective nature of stereotypes can make us self-critical and can encourage us to compare other perspectives and the motives behind them.

Die uitdaging vir die onderwyser van Afrikaans as addisionele taal is om tekste noukeurig te kies en die stereotipes wat daarin voorkom, op wetenskaplike wyse te analiseer, uit te lig en om geleentheid in die klaskamer te skep vir die verwerking van hierdie verskynsel. Dit is veral die letterkunde wat hiertoe 'n bydrae kan lewer.

\subsection{Letterkunde, kultuur en kognitiewe ontwikkeling}

Volgens Robinson (1995:16) kan meer effektiewe kurrikula en metodologie 'n brug bou deur dit wat vir studente bekend is te gebruik as die vertrekpunt om onbekende inhoude op onderrigvlakke in te lei. Robinson 
(1995:16) is oortuig dat die literatuur oor die aanleer van 'n tweede taal erkenning gee aan die belangrikheid daarvan dat kultureel bekende inhoude in sodanige kurrikula ingesluit word as basis vir die ontwikkeling van leesvaardighede, want

... the way students think about things, i.e. the mental operations they perform, is influenced by their own familiarity with the content. Therefore, culturally familiar content is an essential ingredient in introducing the learner to new concepts, linguistic and otherwise, in the second language, foreign language and bilingual classroom.

Moyo (1997:48) meen dat die onderrig van letterkunde ook taalonderrig en kultuuronderrig moet insluit, want die beweging van die bekende na die onbekende kan lei tot kritiese en analitiese denke oor kontensieuse sake wat onder die loep geneem word. Hy wys daarop dat, indien die keuse van letterkundige tekste daarin slaag om sterk positiewe reaksies by die lesers uit te lok, dit kan lei tot 'n genoeglike leerervaring. Die uiteinde daarvan kan 'n lang en blywende positiewe ervaring van die teikentaal wees.

\subsection{Kultuur en nie-verbale kommunikasie}

Morain (in Valdes, 1986:64-76) bespreek die nie-verbale aspekte van kommunikasie (veral liggaamstaal) en noem dit "kinesics" in navolging van Birdwhistell. Dit behoort deel te wees van enige onderrigprogram wat persepsie insluit (by implikasie dus ook die aanleer van 'n addisionele taal). Ook moet dit deel uitmaak van sosiokulturele begrip en interpersoonlike verhoudings. Morain (in Valdes, 1986:64-76) verwys ook na navorsingsbevindings wat daarop dui dat "those who have 'learned' a language without including the nonverbal component are seriously handicapped if they intend to interact with living members of the culture instead of with paper and print".

In hierdie verband kan gekyk word na liggaamstaal en gebaretaal (SuidAfrika se twaalfde erkende landstaal), wat kommunikasiewyses is wat deur mense van verskillende kulture gebruik kan word (alhoewel daar definitief verskille is tussen lande en tale se grammatika van gebaretaal). Ten spyte van die verskille in gebaretaaluitdrukkings, toon dit 'n interessante ooreenkoms met gewone liggaamstaal waarvan elke leerder bewus kan word en wat ' $n$ rol speel in enige interpersoonlike kontak en kommunikasie. Soos wat musiek 'n taal/boodskap het wat deur alle mense gedeel en/of verstaan kan word, kan nie-verbale aspekte en wyses van kommunikasie met vrug in die taalklaskamer gebruik word. Terselfdertyd raak die leerder sensitief vir gevoelens en ervarings van gestremde persone. Taalaanleer word op dié manier deel van die 
alledaagse werklikheid en bly nie net 'n intellektuele oefening vir 'n geïsoleerde kompartement nie.

Die ervaring van 'n belewing (affektief, sosiaal en kultureel) kan uitgedruk word deur beweging. Volgens Katzenellenbogen (1982:46) kan beweging en gebaretaal dikwels kommunikasie moontlik maak waar ander wyses van kommunikasie misluk, want die liggaam dien as die instrument wat benut kan word om deur liggaamshoudings, gebare en liggaamsbewegings idees, gedagtes en gevoelens te beleef en te kommunikeer.

\section{Integrasie van kultuur in 'n kommunikatiewe taalprogram}

Dit is duidelik dat kultuur met vrug benut kan word by die aanleer van 'n addisionele taal. Verskillende elemente van kultuur is uitgelig. Die vraag wat ontstaan, is op watter wyse kultuur in 'n kommunikatiewe taalprogram geïntegreer kan word.

Kamwangamalu $(1997: 246,249)$ redeneer dat dit kultuur is wat taalgebruiksnorme in gemeenskappe bepaal. Hierdie norme sluit in wat om vir wie te sê, wanneer, waar, waarom en hoe. Om hierdie vrae te kan beantwoord en die inhoud te integreer in die leerprogram, is 'n grondige kennis van sosiolinguistiek nodig, wat insig kan bied in sowel die leerder se moedertaalkultuur as die teikentaalkultuur. Hierdie kennis kan bydra tot die addisionele taalspreker se vermoë om die teikentaal korrek en gepas te gebruik.

\subsection{Sosiolinguistiese spraakroetines}

Dit is noodsaaklik dat leerders toegerus word om kruiskultureel te kommunikeer. Dit sluit in dat sowel moedertaalsprekers as teikentaalsprekers verdraagsaamheid aan die dag sal lê wat sosiolinguistiese reëls betref. Wolfson (1989:3) merk op dat Dell Hymes in 1972 die term "kommunikatiewe kompetensie" geformuleer het om te verwys na die vermoë van "... native speakers to use the resources of their language(s) in ways that are not only linguistically accurate but also socially appropriate".

Die kwessie van pragmatiese (sosiolinguistiese) taaloordrag behoort dus aandag te kry. Dit behels dat addisionele-taalleerders hulle moedertaal se sosiolinguistiese spraakreëls gebruik in die teikentaal. Wolfson (1989:156) kom tot die gevolgtrekking dat sosiolinguistiese uitdrukkings nie net in formules geverbaliseer word nie, maar dat dit ook as "ritualized precoded proverbs or expressions" gebruik word, wat nie altyd vertaalbaar is in 'n ander taal of kultuur nie. Hierdie verskynsel vind plaas as gevolg van die verskille in waardes en houdings van die samelewings 
wat daardeur uitgedruk word. Uiteindelik word hier gewys op waardevolle en noodsaaklike kennis waarmee die taalopvoeder toegerus moet word.

Pol Cuvelier van die Universiteit van Antwerpen is saam met die Universiteit van Kaapstad betrokke by ' $n$ projek oor multilingualisme, onderwys en nasiebou (PRAESA). Oor interkulturele kommunikasie berig Cuvelier (2000) dat dit veral gaan

... naar verder uitgraven van de mechanismes in elke interactie: hoe maken mensen die met elkaar een overeenkomst proberen te bereiken ... gebruik van regels en conventies om tot een overeenkomst te komen. Gebruik ze ook 'culturele' frames als referentiepunten?

Cuvelier meen dat binne enige interkulturele interaksiekonteks baie aandag gegee moet word aan die konstruksie van identiteite en kaders. Daarom is dit volgens hom nie genoeg om net iets te weet van die ander se kultuur nie (sulke "culturele weetjes" kan selfs misleidend wees) - 'n mens moet aanvaar dat die leerder altyd in rolle sal kom waarin die ander gespreksvennoot ook weet dat die nie-moedertaalspreker besig is om ' $n$ addisionele taal aan te leer. Daarom is dit belangrik om aandag te gee aan strategieë om probleme te oorbrug (byvoorbeeld wat om te doen as jy 'n woord nie vind nie, hoe om te parafraseer), en te aanvaar dat enige sodanige interaksie gebou word met onvolmaakte middele, omdat niemand ooit werklik 'n tweede/addisionele taal perfek aanleer nie.

Voorbeelde van sosiolinguistiese spraakroetines waaraan in die klaskamer aandag gegee kan word, is die volgende: kennismaak, groet en afskeidneem; dankbetuiging en waardering; verskonings, weiering en apologie; komplimente en reaksies daarop; versoeke en uitnodigings; aanspreek- en beleefdheidsvorme; seksisme.

By die Universiteit van Natal (Durban) het heelwat M.A.-studente reeds gegradueer in die onderrig van Afrikaans as tweede taal. Elkeen van hulle moes in hul omgewing etnografiese navorsing doen oor een van die voorafgenoemde sosiolinguistiese spraakroetines. Dit sou interessant wees om meer van hierdie inligting te publiseer (sommige daarvan het reeds verskyn in die tydskrif Dubbelfluit).

\subsection{Outentieke tekste}

Om sosiolinguistiese kwessies in die addisionele-taalklaskamer aan te raak en te onderrig, kan outentieke materiaal in die taalprogram ingesluit word - die voorwaarde is dat dit universeel van toepassing moet wees 
(Moyo, 1997:47). So word kulturele inligting ingebed in die taalaanleerprogram.

Adaskou et al. (1990:5) se lys van outentieke tekste is 'n uitbreiding van dié van Moyo en dit word aangevul met voorbeelde uit eie ervaring:

- Informatiewe of beskrywende tekste (bv. advertensies, artikels, rubrieke in die media);

- tekste wat houdings en opinies van ander kulture verteenwoordig (bv. meningsopnames in tydskrifte en koerante, film- en boekresensies);

- tekste met inligting oor menslike gebeure (insluitend dialoë), met besonderhede oor die alledaagse lewe (bv. gesprek met 'n kelner in 'n restaurant);

- vraelyste (soos in tydskrifte) oor persoonlikheid, selfbeeld, gewoontes, tradisies;

- idiome en onbekende kollokasies (bv. affektiewe/emotiewe taalgebruik in advertensies, plakkate);

- konvensionele voorbeelde van tekste wat 'n kommunikatiewe funksie het (bv. uitnodigings na troues, gelukwense);

- allerlei realia, of pseudo-realia (bv. spyskaarte, busroosters, fliekgidse, aanwysings om 'n masjien te gebruik);

- enige visuele illustrasies (graptekste, weervoorspellings, strokies, foto's en foto-artikels in die media wat handel oor mense en gebeure in die nuus);

- visuele tekste (skyfieprogramme, straat- of kampusplakkate, TV- en video-materiaal);

- klankopnames (bv. liedjies, radio-onderhoude en -verhale, gesprekke wat leerders self opneem om inligting te versamel).

Candlin (1980:52) verskaf bruikbare inligting en leiding oor die samestelling, reproduksie en gebruik van tekste en media, sowel as die kommunikatiewe vaardighede wat daardeur ontwikkel kan word. Hy lê veral klem op reseptiewe vaardighede wat deur hierdie tekste ontwikkel word, en meen dat die doel van outentieke tekste uit die alledaagse werklikheid is om leerders te motiveer om hul eie gedagtes, opinies en gevoelens te kommunikeer en op grond daarvan produktiewe vaardighede te ontwikkel. Verder beklemtoon hy dat die konteks van die klaskamer meestal kunsmatig en gesimuleer is, terwyl die leerder se werklikheid altyd dinamies en veranderlik is. Dié siening word ondersteun deur Breen (1985:138) en Cuvelier (1999:61). Leerders moet veral vir kommunikasiesituasies in die alledaagse werklikheid toegerus word 
deur middel van interpretatiewe en ekspressiewe aktiwiteite. Le Cordeur (1991:103-126) se studie en aanbevelings oor die gebruik van koeranttekste, spotprente en strokiesprente in stelwerk- en letterkunde-onderrigprogramme kan in hierdie verband dien as bruikbare voorbeelde. Ook Badenhorst (1997) se gebruik van die strokiesprent en Rheeder (2000) se uiteensetting van strokies kan 'n waardevolle bydrae lewer tot die gebruik van hierdie tekste wanneer Afrikaans as addisionele taal onderrig word.

\subsection{Folklore}

Behalwe vir outentieke tekste wat kan help met die ontwikkeling van visuele en ouditiewe vaardighede by die aanleer van Afrikaans as addisionele taal, kan ook gekyk word na die belangrike rol wat letterkundige tekste kan speel, meer spesifiek dan folklore en uiteindelik die bestudering van stereotipes in letterkundige tekste deur middel van die Imagologie.

Die term folklore het 'n wye betekenis en wetenskaplikes (o.a. Dundes, 1965) wat 'n studie hiervan maak, interpreteer die konsep wyd en verskillend, tot so 'n mate dat daar ' $n$ hele folklorewoordeboek is (Leach, 1972). In hierdie artikel word net gekonsentreer op orale uitingsvorme (o.a. volksverhale, spreuke, raaisels, tongknopers, prysliedere en prysname) as voorbeelde van folklore, sowel as volkspele en ander voorbeelde van kultuurdanse.

'n Metode om harmonie in ons veelvolkige land te bereik, is om die hedendaagse leerder voor te berei om interkulturele sensitiwiteit te ontwikkel. Die onderrig van 'n kernliteratuur kan daartoe bydra. Hierdie konsep verwys na al die aktiwiteite en ervarings van menswees wat gedeel word deur die Suid-Afrikaanse gemeenskap. Dit sluit in die ervaring van die mens wat spreek van sy basiese behoeftes, die vermoë om te groei, te voel, te kommunikeer, die werklikheid deur sy verstand te beheers en 'n geestelike dimensie te beleef. Folklore is só 'n tipe kernliteratuur - dit is die oorgelewerde verwoording van die gebeure en waardes wat inherent deel van die mens as spesie is.

Hiermee word gepleit vir die bewuswording en gebruik van folklore (in Afrikaans) binne Afrika-konteks. Belangrike elemente van folklore wat onderskei en analities bekyk kan word in die letterkundeklaskamer waar Afrikaans as addisionele taal aangeleer word, is die volgende:

- Humor: komiese taalgebruik en bedrieëry (bv. "Adoons-hulle" van T.O. Honiball, Jakkals en Wolf-stories, oorspronklike Liewe Heksie- 
stories deur Verna Vels, Apie en Bobbejaantjie-stories deur Helena Lochner);

- magiese-/towerkrag (bv. I.D. du Plessis se verhale, sprokies uit OosAfrika soos "Kaninu se geheim");

- oordrag van sosiale, kulturele waardes en tradisies (bv. oorvertelde, opgetekende outentieke stories, sowel as nuutskeppings);

- antropomorfiese vertellings oor die verband tussen dinge en mense: ekologie, oorsprong (bv. stories van Eugene Marais);

- idiome en wysheidspreuke;

- neologismes (veral kreatiewe samestellings wat uitdrukking gee aan die kultuur van Suid-Afrika sedert die negentigerjare, toe daar 'n renaissance van kennis, tegnologie en informasie tot stand gekom het);

- prysliedere en byname (laasgenoemde moet natuurlik met oorleg en diskresie van die volwasse opvoeder gedoen word, sodat daar op geen manier negatief gediskrimeer word teen individue nie);

- kontrei- en stoepstories (P.G. du Plessis, Jan Spies, Tolla van der Merwe, e.a.).

Uiteindelik kan leerders deur middel van 'n bekende agtergrond/inhoud in 'n teks bewus raak van die omvang van die taal self, met al die diepte en inhoud van betekenis daarin opgesluit. As die lees van 'n teks verstaanbaar is, voel die leser persoonlik betrokke - 'n aspek wat kan lei tot die leser se kreatiewe interaksie met die teks. Hierdie interaksie sluit die meganiese aspek van die taalsisteem en die analitiese aspek daarvan in. Op hierdie wyse kan die leerder deelneem aan die drama, storie, gedig, ensovoorts. So kan die leerder ontdek hoe gebeure ontvou, sy/haar emosionele ervarings deel, en persoonlike reaksie meedeel. Hierin lê die relevansie van 'n goeie leesteks (ongeag die oorsprong), omdat die leerder deel word van die teks en taal op hierdie manier deursigtig word (Moyo, 1997:47).

'n Goeie voorbeeld vir hierdie betoog is Hattingh (1996) se gebruik van die verhaal "Tséane en die perd" (geskryf deur Minnie Postma) in 'n studie met haar Afrikaans-tweedetaalstudente. Hierdie folkloreverhaal is 'n voorstelling van 'n swart vrou wat grootliks afwyk van die gebruiklike etniese stereotipering. Tséane word geteken as rebel. Ten spyte van haar streng tradisionele opvoeding hunker sy na vryheid en 'n ander rol as dié waarin die patriargale samelewing haar wil vasvang. Met dié verhaal het genoemde studente vir die eerste keer kennis gemaak met mondelinge literatuur as belangrike kulturele erfenis van Afrika. Hattingh 
(1996:163) meld dat hierdie verhaal die meeste byval gevind het van al die verhale wat behandel is. Tipiese eienskappe van folklore wat in die verhaal na vore kom, is 'n sterk sin vir die dramatiese, 'n inspeel op die gehoor om meelewing uit te lok, die sang-element en 'n gepaardgaande voorliefde vir herhaling en klankryke frases, die verteller as die wyse ou vrou wat sekere kulturele en sosiale waardes verkondig. Uit Hattingh se verslag is dit duidelik dat hierdie verhaal bygedra het tot kontensieuse gesprekke oor kulturele waardes en persepsies, sowel as die rol daarvan in die hedendaagse samelewing. Sy self meen dat die klemverskuiwing vanaf ' $n$ literêre teksanalise (wat hoofsaaklik kennis van literêre konvensies vereis), na 'n fokus op 'n verskynsel wat ook in die alledaagse lewe op verskillende wyses na vore kom (stereotipering in hierdie geval), die student in staat stel om uit sy/haar eie lewenservaring te put en te groei tot probleemoplossing en selfstandige redenasievermoë (Hattingh, 1996: 167).

Op grond van my eie ervaring met Zoeloe-onderwysstudente is ondervind hoe Afrika-folkloreverhale (o.a. van Minnie Postma en Eugene Marais en sprokies vanuit Oos-Afrika) gespreek het tot die studente, omdat dit nie vir hulle nodig was om te worstel met die agtergrond terwyl hulle woordeskat aangeleer het nie. Hulle kon identifiseer met die karakters en dit is duidelik dat die luister na hierdie stories (en uitgebreide leeswerk daaroor) die volwasse leerders se reseptiewe woordeskat uitbrei en die oordrag na 'n meer aktiewe en produktiewe vorm van taal (praat en skryf) fasiliteer.

By Zoeloesprekende onderwysstudente is volkspele ook met vrug gebruik as instrument om Afrikaans as addisionele taal te onderrig. Die studente kon positief identifiseer met die gevoelselement wat gepaardgaan met hierdie vorm van sosiale dans. Vir hulle was dit 'n bekende kommunikasiemedium waar kultuur deel uitmaak van sosiale interaksie, wat ook verdere dimensies van hulle selfkonsep in ag geneem het. Katzenellenbogen (1999) bespreek volksdans as kreatiewe uitdrukking van (en kennismaking met) kultuur en verduidelik (Katzenellenbogen, 1982: 50) dat dans as motivering vir sosiale gedrag en interaksie gesetel mag wees in die blote genot om saam met ander te beweeg (ekspressie), en om alleen of gesamentlik die betekenis van saam beweeg aan ander oor te dra (kommunikasie).

\subsection{Imagologie en die bestudering van stereotipes in letterkunde}

Die multikulturaliteit van die Suid-Afrikaanse samelewing bring mee dat elke gemeenskap op sy eie manier gestalte gee aan universele waardes en idees. By die bestudering van letterkundige tekste sal die onderwyser in die tweedetaalklaskamer versigtig moet wees om die leerlinge te lei in 
die ontdekking en studie van die betrokke waardes wat elke leerder in die klas met hom saambring, sodat niemand aanstoot neem nie.

Hattingh (1996) doen verslag van klasaktiwiteite wat sy aangepak het in 'n letterkundestudie met stereotipering as tema (met Afrikaans-tweedetaalstudente by die Universiteit van Wes-Kaapland). Die taalonderrig in dié studie het gefokus op interkulturele verhoudings wat 'n groot rol kan speel om leerders bewus te maak en te bevry van etnies-gesentreerde stereotipering. Sy stel dat die studente gevoel het

... dat die lees van die verhale uit die perspektief van stereotipering hulle nie net met 'n kritiese leesstrategie laat kennis maak het nie, maar hulle werklik tot selfondersoek gedwing het ... [en] ... hulle [het] betrokke gevoel by die proses van betekenisskepping (Hattingh, 1996:167).

Terwyl die Suid-Afrikaanse gemeenskap steeds verdeel is in verskillende etniese groepe omrede polities-historiese redes, bestaan die SuidAfrikaanse identiteit uit 'n pluraliteit van Self-Ander-verhoudings met 'n historiese konflik in waardes tussen die verskillende kulture. 'n Kennis en begrip van die Self en die Ander in die veeltalige klaskamer (of selfs die kultuur buite die formele leersituasie) kan bydra tot wedersydse begrip en respek.

Een van die voordele van letterkunde-onderrig kan gevind word in die feit dat leerders die geleentheid kry om letterkundige beelde van die Self en die Ander te ontmoet, beelde wat nie die selfbeeld bedreig nie. Binne so 'n teoretiese raamwerk kan die addisionele-taalleerder kennis maak met ander kulture en die relatiwiteit van waardes. Vanuit die betrokkenheid by waardesisteme is die Imagologie volgens Syndram (1991:191) in 'n posisie om stabiliserende prosesse en taksonomiese modelle in artistieke, kulturele en nasionale beleid te analiseer en met mekaar in verband te bring. Die imagologie werk op 'n historiese en vergelykende basis met die resepsie van letterkunde. 'n Imagologiese studie van jeugletterkunde kan byvoorbeeld bydra tot die proses van interkulturele konfrontasie wat op sy beurt kan lei tot interkulturele begrip.

Elders (Kruger, 1994) word verslag gedoen van die wyse waarop leerders Wit Oemfaan (F.A. Venter) ervaar het en hoe die gebruik van hierdie teks binne 'n kommunikatiewe letterkunde-onderrigmodel gelei het tot in-diepte-gesprekke oor interkulturele versoenbaarheid. Deur middel van 'n imagologiese analise van die stereotipes in hierdie teks (Kruger, 1996) is die studente aangemoedig om gespreksgenote te word deur aktiewe interaksie en in die proses te ervaar dat die teks hulle 
uitdaag om hul eie en ander se stereotipes raak te sien, daaroor na te dink en dit te verwerk.

In 'n verdienstelike bespreking van Vatmaar (A.H.M. Scholtz) bestudeer Nieman (1998:127) die teks as 'n storie van identiteit en alteriteit, van komplekse verhoudings tussen die Self (kleurlinginwoners van Du Toitspan) en die Ander (wit mense). Verder analiseer Nieman hierdie roman binne 'n imagologiese raamwerk en toon aan hoe die gestereotipeerde beelde van verskillende kultuurgroepe in die teks gebruik kan word in 'n multikulturele taalklaskamer waar Afrikaans aangeleer word. Nieman meld ook hoe hierdie teks gunstig gebruik kan word in die uitkomsgebaseerde onderwysbenadering (Nieman, 1998:139-140).

\section{Ten slotte}

Die kurrikulum omvat die formele en informele inhoud en proses waardeur leerders kennis en begrip opdoen, vaardighede ontwikkel, en houdings sowel as waardes aanpas.

Daar is behoefte aan die insluiting van 'n kulturele komponent in die leerprogram van Afrikaans as addisionele taal. Hierdie verruiming van leerinhoud deur middel van sosiolinguistiese spraakroetines, outentieke tekste, folklore en die imagologiese bestudering van stereotipes kan help om die negatiewe bagasie wat Afrikaans dra te neutraliseer, omdat die nie-moedertaalleerders se belangstellings en behoeftes geprikkel en betrek kan word. Die pad na nie-moedertaalsprekers se verstand en die aanleer van 'n vreemde taal loop deur hulle harte - daar waar hulle voel, dramatiseer, naboots, dans, lag en sing. As hulle tuis voel in die Afrikaans-klaskamer, sal hulle aktief leer en deelneem, en boweal verantwoordelikheid aanvaar vir hul eie leerproses - omdat dit prettig, genotvol en betekenisvol vir hulle alledaagse lewenswerklikheid is.

As 'n mens die metafoor gebruik van die apies (wat nie sien, hoor, sê en doen wat sleg is nie), kan opvoeders hulle wel onttrek van kulturele inhoude wat tot dusver taboe was - omdat daar waarskuwingseine en rooi ligte is wat aangaan oor alles wat verkeerd kan wees. Maar alhoewel kulturele inhoude soms (soos veral in ons nabye verlede) negatief geïnterpreteer is, bevat dit baie potensiaal om verrykend en dinamies te kan wees - as opvoeders sensitief en gebalanseerd daarmee kan omgaan. Tasbare, sigbare kultuuruitings is ' $n$ ryk bron van kulturele geletterdheid en kultuurskepping wat wag om ontgin te word. 


\section{Bibliografie}

Adaskou, K., Britten, D. \& Fahsi, B. 1990. Design decisions on the cultural content of a secondary English course for Morocco. The English Language Teaching Journal, 44(1):3-10.

Badenhorst, A. 1997. Die benutting van die strokiesprent in die onderrig van Afrikaanse stelwerk en letterkunde op sekondêre vlak. Stellenbosch : Universiteit van Stellenbosch. (M. Ed.-verhandeling.)

Bredella, L. \& Haack, D. 1988. Perceptions and misperceptions: the United States and Germany. Tübingen : Gunter Narr Verlag.

Breen, M.P. 1985. The social context for language learning - a neglected situation? Studies in Second Language Acquisition, 7:135-158.

Candlin, C.N. (ed.) 1980. The communicative teaching of English: principles and an exercise typology. Essex : Longman.

Combrink, L. 1996. Kulturele geletterdheid en multikulturele onderwys. Tydskrif vir Taalonderrig, 30(1):1-13.

Cuvelier, P. 1999. Intercultural communication. A short course on intercultural communicative competence for teachers. Ongepubliseerde studiehandleiding vir Verdere Onderwysdiploma, Universiteit van Kaapstad.

Cuvelier, P. (cuvelier@iua.ua.ac.be).2000. Studie oor interkulturele kommunikasie. [E-pos aan E. Kruger (ekruger@sacte.ac.za)]. April 5.

Department of Education. 1997. Policy document: Senior Phase (grades 7 to 9). Pretoria.

Dundes, A. 1965. The study of folklore. Englewood Cliffs, NJ : Prentice-Hall.

Hamersma, E. 1997. Afrikaans as 'n vreemde taal in Suid-Afrikaanse skole: slaggate en uitdagings. Tydskrif vir Taalonderrig, 31(4): 284-291.

Hattingh, M. 1996. Stereotipering as aanknopingspunt by die lees van Afrikaanse kortverhale in 'n multikulturele klas. Stilet, 8:155-169.

Kamwangamalu, N. 1997. English and transformation to multicultural education in the new South Africa. Journal for Language Teaching, 31(3):243-252.

Katzenellenbogen, E. 1982. Beweging - 'n nie-verbale kommunikasiemiddel. In: Amusa, L.O., Toriola, A.L. \& Onyewadume, I.U. Liggaamsbeweging en diemens-in-wording. Bundel referate gelewer by Nasionale Simposium: Liggaamlike Opvoedkunde. Universiteit van Pretoria. p. 45-52.

Katzenellenbogen, E. 1999. Educational dance in a Physical Education curriculum. In: Physical Education and Sport in Africa. Ibadan : LAP Publications. p. 85-120.

Kruger, E. 1994. Die gebruik van Wit Oemfaan (F.A. Venter) as teks in 'n kommunikatiewe letterkunde-onderrigmodel. In: Vernuwing in die Afrikaanse letterkunde. Bundel referate gelewer tydens die Afrikaanse Letterkunde Verenigingkongres, Port Elizabeth. p. 311-322.

Kruger, E. 1996. 'n Imagologiese analise: F.A. Venter se Wit Oemfaan in die Afrikaans tweedetaalklaskamer. Durban : Universiteit van Natal. (M.A.navorsingsartikel.)

Leach, M. (ed). 1972. Standard dictionary of folklore, mythology and legend. Toronto : Funk \& Wagnalls Publishing.

Le Cordeur, M.L.A. 1991. Die integrasie van stelwerk- en letterkunde-onderrig met toespitsing op die media. Stellenbosch : Universiteit van Stellenbosch. (M. Ed.verhandeling.)

Lessing, A.C. \& De Witt, M.W. 1999. Riglyne vir die samestelling van 'n leesprogram vir T2-leerders. Tydskrif vir Taalonderrig, 33(1):46-59.

Moyo, T. 1997. Are the current high school literature texts of relevance to the culture of ESL learners? Tydskrif vir Taalonderrig, 31(1):42-49. 
Nieman, M.M. 1998. Vatmaar raakgevat vir tweedetaalonderrig in 'n multikulturele klaskamer. Tydskrif vir Taalonderrig, 32(2):127-141.

Rheeder, A.O.I. 2000. Bitterkomix: Teks, konteks, interteks, en die literêre strokies van Conrad Botes en Anton Kannemeyer. Stellenbosch : Universiteit van Stellenbosch. (M.A.-verhandeling.)

Robinson, G.L.N. 1995. Crosscultural understanding: Processes and approaches for foreign language, English as a second language and bilingual educators. New York : Pergamon Institute of English.

Syndram, K.U. 1991. The aesthetics of alterity: Literature and the imagological approach. In: Leerssen, J.T. \& Spiering, M. National identity - symbol and representation. Yearbook of European Studies 4. Amsterdam : Rodopi. p. 177191.

Trivedi, H.C. 1978. Culture in language learning. English Language Teaching Journal, 32(2):92-97.

Valdes, J.M. 1986. Culture bound - bridging the cultural gap in language teaching. New York : Cambridge University Press.

Wolfson, N. 1989. Perspectives, Sociolinguistics and TESOL. New York : Newbury House.

Zulu, N.S. 1996. Teaching ESL literature: the problems of cultural selection in South Africa. Tydskrif vir Taalonderrig, 30(1):50-58.

\section{Kernbegrippe:}

addisionele-taalkurrikulum

folklore; rol van

interkulturele begrip

kulturele komponent by die aanleer van taal

\section{Key concepts:}

additional-language curriculum

cultural component in language acquisition

folklore; role of

intercultural comprehension 